\title{
Position of Sediments in Transfer of Radionuclides Released into Coastal Sea to Human Beings
}

\author{
Taishi Ueda, ${ }^{*}$ Ryoichi Nakamura, ${ }^{*}$ and Yuzuru Suzuki* \\ (Accepted January 10, 1985)
}

\begin{abstract}
A great portion of radionuclides released into coastal sea is adsorbed into marine sediments and the adsorbed radionuclides causes the radioactive contamination of marine organisms and then transferred to human beings who consume them. In order to make a quantitative evaluation of this route, the transfer of 9 kinds of radionuclides from sediments to benthic organisms such as algae, bivalve and worm was observed. Then it was compared with the radioactivity in these organisms from radioactively contaminated sea water (Concentration factor). It was observed that the influence of sea water was larger than that of sediments as it was $10^{4}$ times larger for ${ }^{54} \mathrm{Mn}, 10^{3}$ times larger for ${ }^{56} \mathrm{Fe},{ }^{80} \mathrm{Co},{ }^{85} \mathrm{Zr}-{ }^{85} \mathrm{Nb},{ }^{108} \mathrm{Ru}-{ }^{108} \mathrm{Rh}$ and ${ }^{144} \mathrm{Ce}-{ }^{144} \mathrm{Pr}, 10^{2}$ times larger for ${ }^{63} \mathrm{Zn}$ and $10-10^{2}$ times larger for ${ }^{115 m} \mathrm{Cd}$ and ${ }^{137} \mathrm{Cs}$.

Consequently, sea water can be considered as the main route and sediments as the secondary in the case of quantitative comparison of the effect on the accumulation of radionuclides by marine organisms and in the transfer of radionuclides to human beings.
\end{abstract}

It is well known that marine sediments accumulate radionuclides as much as toxic metals and there are several reports on the sedimentsbiota interaction. ${ }^{1-7)}$ But it is still not clear the position of sediments in the transfer process of radionuclides from nuclear facilities to human begins via marine products.

The authors have been studied this problem by obtaining 1) transfer of radionuclides from contaminated sediments to marine organisms such as algae, bivalve and worm which are benthic and closely contact with sediments and 2) accumulation of radionuclides by marine organisms from sea water. The influences of sediments and sea water on radioactive contamination of organisms were estimated by comparing 1) and 2). Several studies on ${ }^{80} \mathrm{Co},{ }^{85} \mathrm{Zr}-{ }^{95} \mathrm{Nb},{ }^{100} \mathrm{Ru}-{ }^{100} \mathrm{Rh},{ }^{115 \mathrm{~m}} \mathrm{Cd}$ and ${ }^{137} \mathrm{Cs}$ have been reported previously. ${ }^{8-12}$ ) In this paper, study on ${ }^{54} \mathrm{Mn},{ }^{50} \mathrm{Fe},{ }^{85} \mathrm{Zn}$ and ${ }^{144} \mathrm{Ce}-$ ${ }^{144} \mathrm{Pr}$ is mainly reported together with summary of the former 5 radionuclides in the previous reports by us.

\section{Materials and Methods}

Radionuclides used were the following 9 kinds: ${ }^{54} \mathrm{Mn}\left(\mathrm{MnCl}_{2}\right), \quad{ }^{50} \mathrm{Fe}\left(\mathrm{FeCl}_{3}\right), \quad{ }^{60} \mathrm{Co}\left(\mathrm{CoCl}_{2}\right),{ }^{85} \mathrm{Zn}$ $\left(\mathrm{ZnCl}_{2}\right)$, ${ }^{85} \mathrm{Zr}-{ }^{95} \mathrm{Nb}\left[\mathrm{Zr}(\mathrm{COO})_{2}\right], \quad{ }^{108} \mathrm{Ru}-{ }^{106} \mathrm{Rh}$ (nitrosylruthenium nitrato complexes), ${ }^{115 \mathrm{~m}} \mathrm{Cd}$
$\left(\mathrm{CdCl}_{2}\right),{ }^{137} \mathrm{Cs}(\mathrm{CsCl})$ and ${ }^{144} \mathrm{Ce}^{-144} \mathrm{Pr}\left(\mathrm{CeCl}_{3}\right)$, and with the exception of the specific activity of $93 \mathrm{mCi} /$ $\mathrm{mg} \mathrm{Co}$ for ${ }^{\circ 0} \mathrm{Co}$ and $0.12 \mathrm{mCi} / \mathrm{mg} \mathrm{Cd}$ for ${ }^{115 \mathrm{~m}} \mathrm{Cd}$, the other radionuclides were carrier-free.

All experiments were performed at room temperature.

Experiment 1. Transfer of radionuclides from sediments to organisms (Transfer ratio).

The sediments were sieved immediately after sampling from the intertidal zone of the seashore around Ajigaura in Nakaminato city and the $0.1-0.5 \mathrm{~mm}$ diameter portion was used. The portion accounts for $90 \%$ of the sediments. Sea water was used after filtration with a filter paper (Toyo, No. 5C).

To obtain contaminated sediments, $100 \mathrm{~g}$ of sediments and $300 \mathrm{ml}$ of sea water were placed in $1 l$ polyethylene bottle, each radionuclide $(0.2 \mathrm{mCi})$ added separately and shaken horizontally at a rate of 100 times per min with aeration. After exposure for one week, sediments were washed 3 times with non-radioactive sea water by decantation and the radioactivity was measured with a whole body counter (Armac Liquid Scintillation Counter, Model 446, Packard).

Eighty grams of the contaminated sediments and $800 \mathrm{ml}$ of fresh sea water (quantity ratio $1: 10$ ) were placed in $5 l$ capped acrylic tank and or-

* Division of Marine Radioecology, National Institute of Radiological Sciences, 3609 Nakaminato, Ibaraki

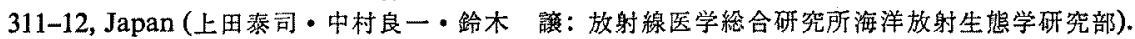


ganisms were reared in the tank with aeration. The radioactivity in organisms was measured with the whole body counter. Three bivalves (Gomphina melanaegis, average body weight: $30 \mathrm{~g}$ ) were dissected and the soft parts were submitted to the radioactivity measurement. In the case of marine algae (Chondrus sp., Hijikia fusiforme, Sargassum thunbergii, Ahnfeltia sp. and Gracilaria verrucosa), about $4 \mathrm{~g}$ were reared for each radionuclide. A portion of algae was taken on the day of the measurement and washed for $2 \mathrm{~min}$ with non-radioactive sea water. After removing sea water on the surface of algae with filter paper, the radioactivity of algae was measured with the whole body counter.

The ratio of radioactivity in organisms to the initial radioactivity in sediments was expressed as "Transfer ratio".

Experiment 2. Accumulation of radionulides by marine organisms from sea water (Concentration factor).

Each $2 \mu \mathrm{Ci}$ of the radionuclides was separately added to $5 l$ of sea water in acrylic tank and aerated. The radioactivity in sea water was kept at the steady level by the addition of radionuclide. Bivalves and algae mentioned above were reared in the tank and their radioactivity was measured
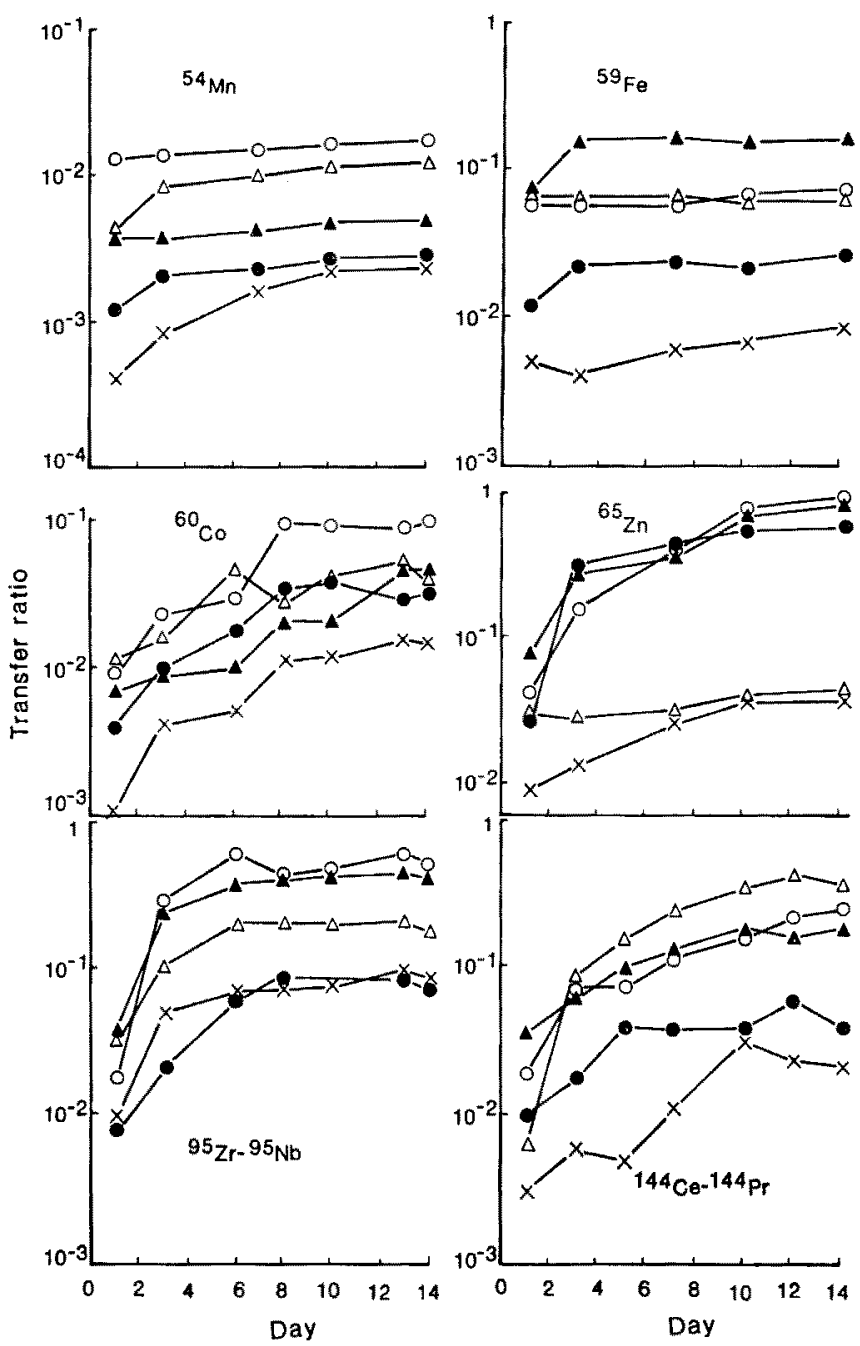

Fig. 1. Transfer of radionuclides from sediments to algae.

$\bigcirc-O$ Sargassum thunbergii, $\Delta-\Delta$ Gracilaria verrucosa, - Chondrus $\mathrm{sp}$., A-A Ahnfeltia sp. $\times-\times$ Hijikia fusiforme. 
with the whole body counter. Measurement of sea water was carried out by taking $2 \mathrm{ml}$ in a polyethylene test tube with the whole body counter. The ratio of the radioactivity in organisms to that in sea water was presented as concentration factor.

For the calculation of concentration factor and transfer ratio, the values of organisms on the 14th day were used in Experiment 1 and 2.

To express the comparative influence of sediments and sea water on the accumulation of radionuclide by organisms, BFS (Biological Factor of the Sediments) is used here dividing the concentration factor with the transfer ratio.

\section{Results}

Experiment 1. Transfer of radionuclides from sediments to organisms (Transfer ratio).

Fig. 1 shows the transfer of radionuclides from sediments to algae (Transfer ratio). With the exception of ${ }^{65} \mathrm{Zn}$, the radioactivity in Hijikia fusiforme and Chondrus sp. is low, while that in Ahnfeltia sp. and Sargassum thunbergii indicates high values. The transfer of radionuclides from sediments to bivalves is shown in Fig. 2 as transfer ratio. The transfer ratios of bivalve are in the range $10^{-2}$ to $10^{-3}$ and these are much lower than those of algae.

Experiment 2. Accumulation of radionuclides by marine organisms from sea water (Concentration factor).

The accumulation of radionuclides from sea water by algae is shown in Fig. 3 as concentration factor. The accumulation by Hijikia fusiforme was

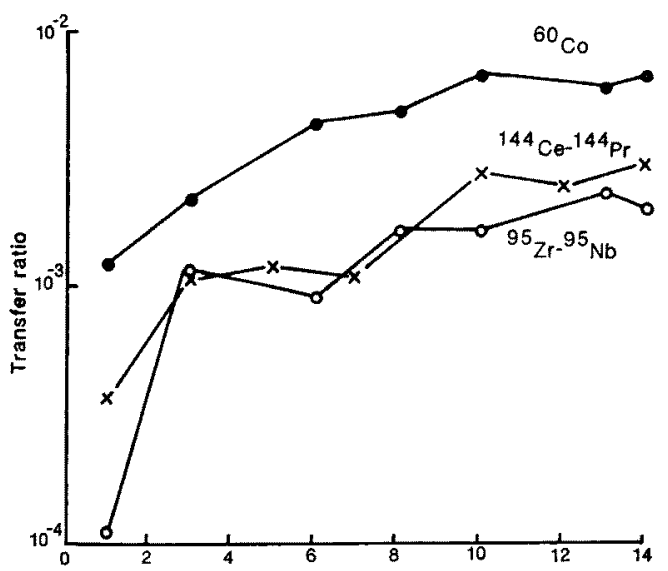

Fig. 2. Transfer of radionuclides from sediments to bivalve Gomphina melanaegis. lowest in the algae. Sargassum thunbergii indicated the largest concentration factor with the exception of ${ }^{85} \mathrm{Zn}$ and ${ }^{144} \mathrm{Ce}-{ }^{144} \mathrm{Pr}$. The concentration factors for bivalve are shown in Fig. 4. The concentration factor of ${ }^{60} \mathrm{Co}$ was larger than those of ${ }^{144} \mathrm{Ce}-{ }^{144} \mathrm{Pr}$ and ${ }^{85} \mathrm{Zr}-{ }^{85} \mathrm{Nb}$. The concentration factors for bivalve were lower than those for algae.

\section{Discussion}

The results from Experiment 1 and 2 are summarized in Table 1, accompanying previous data by us. ${ }^{10-12}$ The transfer ratio of radionuclides is in a range of 0.857 for ${ }^{8 x} \mathrm{Zn}$ in the case of Sargassum thunbergii and 0.001 for ${ }^{100} \mathrm{Ru}-{ }^{100} \mathrm{Rh}$ in the case of Gomphina melanaegis and the concentration factor is in a range from 2680 (Gracilaria verrucosa for ${ }^{144} \mathrm{Ce}-{ }^{144} \mathrm{Pr}$ ) to 2 (Gomphina melanaegis for ${ }^{100} \mathrm{Ru}-{ }^{100} \mathrm{Rh}$ ). The BFS values are in the order of $10^{4}$ for ${ }^{54} \mathrm{Mn}, 10^{3}$ for ${ }^{58} \mathrm{Fe},{ }^{95} \mathrm{Zr}-{ }^{95} \mathrm{Nb}$, ${ }^{144} \mathrm{Ce}-{ }^{144} \mathrm{Pr}$ and ${ }^{100} \mathrm{Ru}-{ }^{108} \mathrm{Rh}, 10^{2}$ for ${ }^{85} \mathrm{Zn}$ and ${ }^{115 \mathrm{~m}} \mathrm{Cd}, 10-10^{2}$ for ${ }^{137} \mathrm{Cs}$ and $10^{2}-10^{4}$ for ${ }^{60} \mathrm{Co}$. From these figures, it could be said that sea water gives organisms $10^{4}$ times higher radioactivity than sediments in the accumulation of ${ }^{84} \mathrm{Mn}$ by organisms and $10-10^{2}$ times higher radioactivity of ${ }^{137} \mathrm{Cs}$ when the radioactivity in sediments is the same level as in sea water. The quantity ratio of sediments and sea water in Experiment 1 is $1: 10$ but the transfer ratio differs when this ratio is changed. In the previous report by us, ${ }^{1 i}$ ) the transfer ratio decreased to about $1 / 3$ when the quantity ratio was changed from $1: 100$ to $1: 400$. If a radionuclide is adsorbed to $2 \mathrm{~cm}$ depth of surface layer of the sediments and the specific gravity of the sediments is taken as 2 , the ratio of $1: 10,1: 100$ and $1: 400$ indicates water depth of $0.4,4$ and 16 meter, respectively. In this experiment, the quantity ratio corresponded to the shallow sea with $0.4 \mathrm{~m}$ depth was used to estimate the influence of sediments as much as possible. Nevertheless, concentration factors are larger than transfer ratios. This means that sea water affects the accumulation of radionuclides by organisms more than sediments when the radioactivity in sea water is equal to that in sediments. But the authors previously reported that ${ }^{\circ 0} \mathrm{Co}$ in Sargassum fluvellum came from radioactive sediments, ${ }^{13)}$ and Seymour and Nelson ${ }^{14)}$ detected ${ }^{85} \mathrm{Zn}$ in mussel after shutdown of nuclear generator. Therefore, the possibility of contamination of organisms by sediments could not be neglected when the radioactivity in sea water is 

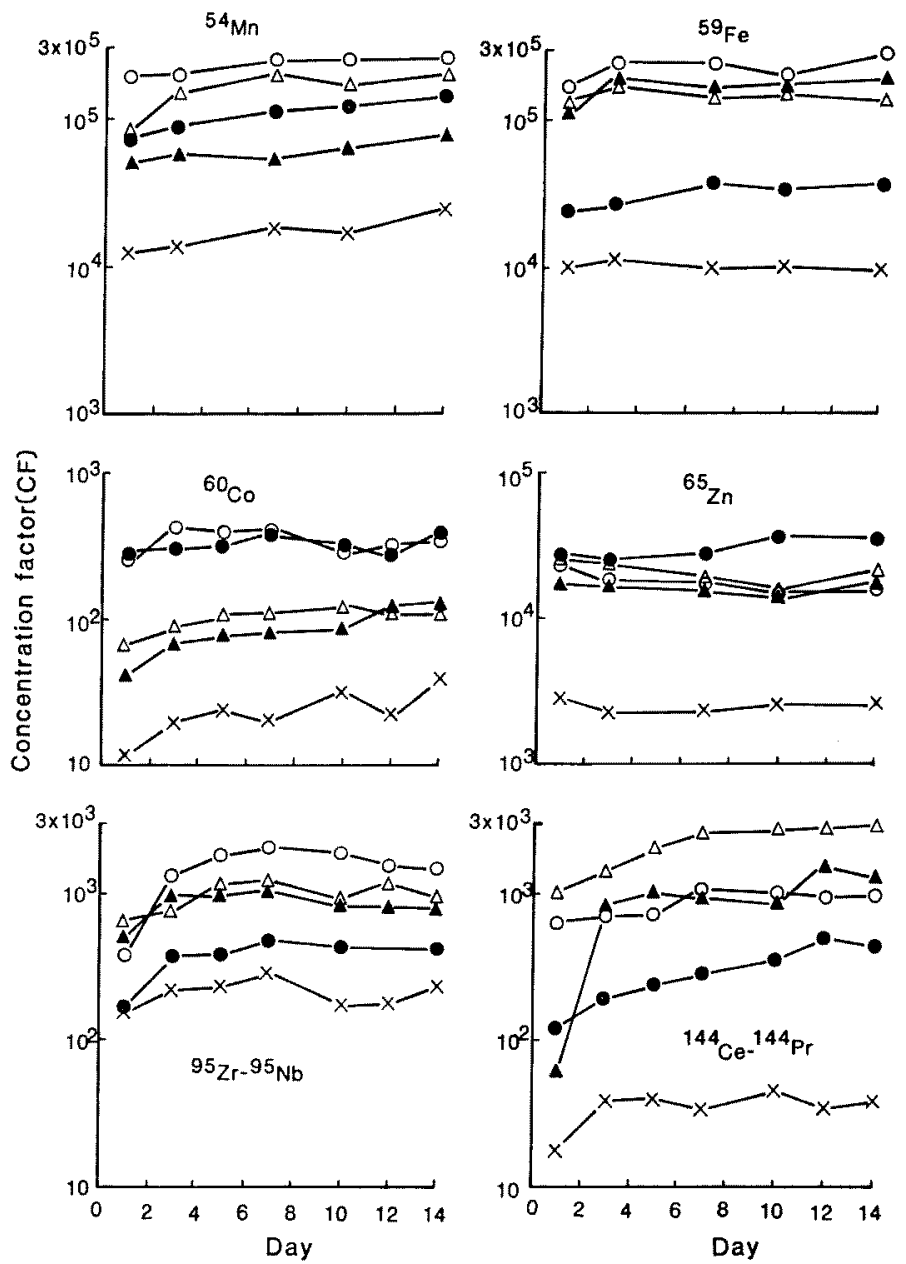

Fig. 3. Accumulation of radionuclides from sea water by algae.

$\bigcirc-O$ Sargassum thunbergii, $\triangle \longrightarrow \triangle$ Gracilaria verrucosa, \-Ahnfeltia sp. $\times \longrightarrow \times$ Hijikia fusiforme

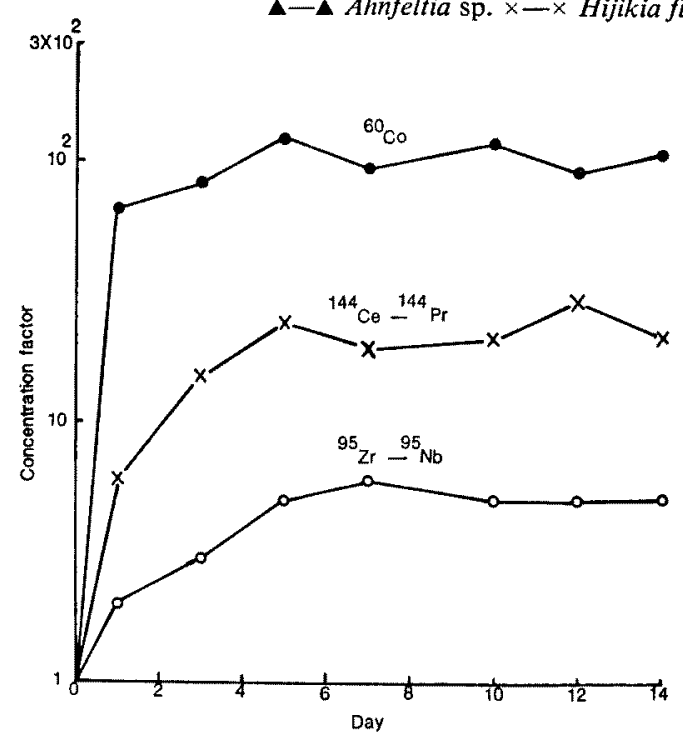

reduced. However, in general, it could be said that sea water affects the accumulation of radionuclides more than sediments.

In conclusion, the flux of radionuclides released into coastal sea can be considered as shown in Fig. 5.

I) Radionuclide along route A considerably differs depending on whether the topography of the coast is of the closed type or the open type facing the ocean.

II) Another portion remains in the coastal sea water and causes the radioactive contamination of organisms depending on concentration factors (route B).

Fig. 4. Accumulation of radionuclides from sea water by bivalve Gomphina melanaegis. 
Table 1. Accumulation of radionuclides from sediments and sea water by marine organisms

\begin{tabular}{|c|c|c|c|c|c|c|c|}
\hline Radionuclide & $\begin{array}{c}\text { (A) } \\
\text { Initial } \\
\text { concen- } \\
\text { tration in } \\
\text { sediments } \\
(\mathrm{cpm} / \mathrm{g})\end{array}$ & & Organism & $\begin{array}{l}\text { (B) } \\
\text { Concen- } \\
\text { tration in } \\
\text { organisms } \\
(\mathrm{cpm} / \mathrm{g})\end{array}$ & $\begin{array}{l}(\mathrm{C}) \\
\text { Transfer } \\
\text { ratio } \\
(\mathrm{B} / \mathrm{A})\end{array}$ & $\begin{array}{l}\text { (D) } \\
\text { Concen- } \\
\text { tration } \\
\text { factor }\end{array}$ & $\begin{array}{c}\text { (E) } \\
\text { BFS } \\
\text { (D/C) }\end{array}$ \\
\hline \multirow[t]{6}{*}{${ }^{54} \mathrm{Mn}$} & & Algae & Chondrus sp. & 30280 & 0.027 & 1320 & 48890 \\
\hline & & & Hijikia fusiforme & 26260 & 0.023 & 240 & 10400 \\
\hline & 1142000 & & Sargassum thunbergii & 184400 & 0.162 & 2410 & 15700 \\
\hline & & & Ahnfeltia sp. & 52500 & 0.046 & 720 & 15700 \\
\hline & & & Gracilaria verrucosa & 130200 & 0.114 & 1970 & 17300 \\
\hline & & Bivalve & Gomphina melanaegis & 7050 & 0.006 & 150 & 25000 \\
\hline \multirow[t]{6}{*}{${ }^{59} \mathrm{Fe}$} & & Algae & Chondrus sp. & 7800 & 0.027 & 150 & 5560 \\
\hline & & & Hijikia fusiforme & 2600 & 0.009 & 20 & 2220 \\
\hline & 284000 & & Sargassum thunbergii & 21700 & 0.076 & 500 & 6580 \\
\hline & & & Ahnfeltia sp. & 45600 & 0.161 & 340 & 2110 \\
\hline & & & Gracilaria verrucosa & 17500 & 0.062 & 240 & 3870 \\
\hline & & Bivalve & Gomphina melanaegis & 560 & 0.002 & 100 & 5000 \\
\hline \multirow[t]{7}{*}{${ }^{80} \mathrm{Co}$} & & Algae & Chondrus sp. & 61500 & 0.032 & 370 & 12330 \\
\hline & & & Hijikia fusiforme & 62900 & 0.033 & 40 & 1210 \\
\hline & 1907000 & & Sargassum thunbergii & 25490 & 0.134 & 330 & 2460 \\
\hline & & & Ahnfeltia sp. & 63800 & 0.033 & 120 & 3460 \\
\hline & & & Gracilaria verrucosa & 83900 & 0.044 & 110 & 2500 \\
\hline & & Bivalve & Gomphina melanaegis & 13000 & 0.007 & 110 & 15710 \\
\hline & & Worm & Nereis japonica & 95400 & 0.050 & 6 & 120 \\
\hline \multirow[t]{6}{*}{${ }^{65} \mathrm{Zn}$} & & Algae & Chondrus sp. & 84800 & 0.558 & 260 & 470 \\
\hline & & & Hijikia fusiforme & 5500 & 0.036 & 20 & 560 \\
\hline & 152000 & & Sargassum thunbergii & 130300 & 0.857 & 120 & 140 \\
\hline & & & Ahnfeltia sp. & 126200 & 0.830 & 130 & 160 \\
\hline & & & Gracilaria verrucosa & 64400 & 0.424 & 170 & 400 \\
\hline & & Bivalve & Gomphina melanaegis & 6100 & 0.040 & 20 & 500 \\
\hline \multirow[t]{7}{*}{${ }^{85} \mathrm{Zr}-{ }^{85} \mathrm{Nb}^{*}$} & & Algae & Chondrus sp. & 73000 & 0.065 & 410 & 6200 \\
\hline & & & Hijikia fusiforme & 86700 & 0.078 & 230 & 2950 \\
\hline & 1118000 & & Sargassum thunbergii & 521500 & 0.466 & 1390 & 2980 \\
\hline & & & Ahnfeltia sp. & 419900 & 0.376 & 760 & 2020 \\
\hline & & & Gracilaria verrucosa & 183400 & 0.164 & 870 & 5300 \\
\hline & & Bivalve & Gomphina melanaegis & 1900 & 0.002 & 5 & 2500 \\
\hline & & Worm & Nereis japonica & 10100 & 0.009 & 4 & 440 \\
\hline \multirow{3}{*}{${ }^{108} \mathrm{Ru}-{ }^{108} \mathrm{Rh}^{*}$} & & Algae & Cyrtymenia sp. & 59000 & 0.054 & 290 & 5400 \\
\hline & 1095000 & Bivalve & Gomphina melanaegis & 820 & 0.001 & 2 & 2000 \\
\hline & & Worm & Nereis japonica & 65700 & 0.060 & 6 & 1000 \\
\hline${ }^{115} \mathrm{~m} \mathrm{Cd}^{*}$ & 18000 & Worm & Nereis japonica & 2200 & 0.122 & 22 & 180 \\
\hline \multirow{3}{*}{${ }^{137} \mathrm{Cs}^{*}$} & & Algae & Cyrtymenia sp. & 81000 & 0.069 & 5 & 70 \\
\hline & 1182000 & Bivalve & Gomphina melanaegis & 53000 & 0.045 & 7 & 160 \\
\hline & & Worm & Nereis japonica & 211600 & 0.179 & 6 & 40 \\
\hline \multirow[t]{6}{*}{${ }^{144} \mathrm{Ce}-{ }^{144} \mathrm{Pr} *$} & & Algae & Chondrus sp. & 62700 & 0.039 & 420 & 10800 \\
\hline & & & Hijikia fusiforme & 34000 & 0.021 & 40 & 1900 \\
\hline & 1617000 & & Sargassum thunbergii & 395800 & 0.245 & 910 & 3700 \\
\hline & & & Ahnfeltia sp. & 299600 & 0.185 & 1230 & 6650 \\
\hline & & & Gracilaria verrucosa & 577000 & 0.357 & 2680 & 7500 \\
\hline & & Bivalve & Gomphina melanaegis & 4400 & 0.003 & 20 & 6670 \\
\hline
\end{tabular}




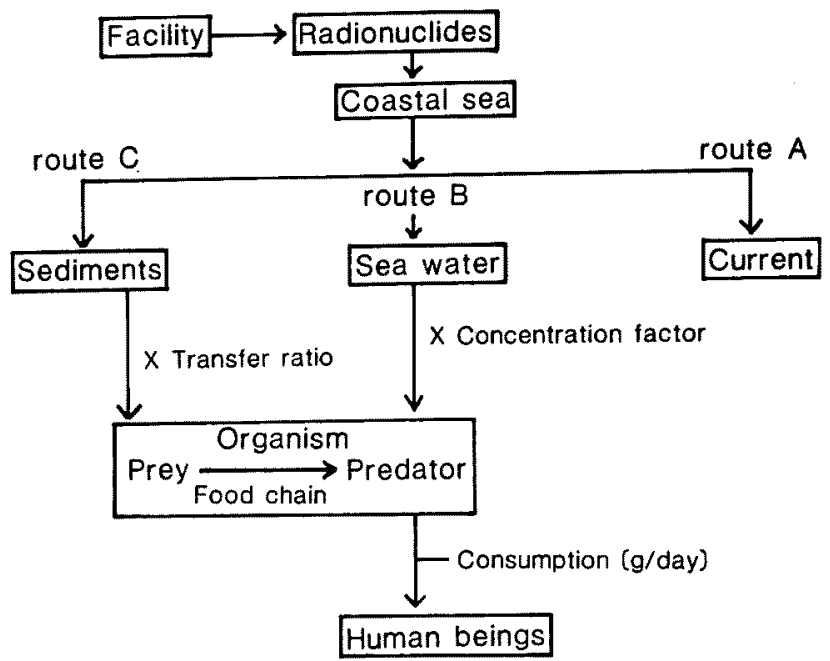

Fig. 5. Flux of radionuclides released into coastal sea.

III) The balance is adsorbed to sediments and radionuclides recycled from sediments causes the radioactive contamination of organisms (route $\mathrm{C}$ ).

In the transfer of radionuclides to human beings via marine organisms, the primary is route $\mathbf{B}$ and the secondary is route $C$, although sediments adsorb a great portion of radionuclides released into coastal sea. ${ }^{8,8)}$

\section{References}

1) R. F. Jones: Limnol. Oceanogr., 5, 312-325 (1960).

2) E. Cerrai, B. Schreiber, and C. Triulzi: Energ. Nucl., 14, 586-592 (1967).

3) E. K. Duursma and M. G. Gross: in "Radioactivity in the Marine Environment" National Academy of Sciences, Wash., D.C., 1971, pp. 147160.

4) F. G. Lowman, T. R. Rice, and F. A. RichaRds: in "Radioactivity in the Marine Environment" National Academy of Sciences, Wash., D.C., 1971, pp. 161-199.
5) V. T. Bowen, J. S. Olsen, C. L. Osterberg, and J. RAVERA: in "Radioactivity in the Marine Environment" National Academy of Sciences, Wash., D.C., 1971, pp. 200-222.

6) M. G. Gross: in "The Columbia River Estuary and Adjacent Ocean Water" (ed. by A. T. PRUTzR and D. L. Alverson), Univ. Wash. Press, Seattle and London, 1973, pp. 736-754.

7) W. C. Renfro: Mar. Biol., 21, 305-316 (1973).

8) R. Nakamura, Y. Suzuki, and T. Ueda: $J$. Radiat. Res., 16, 224-236 (1975).

9) R. Nakamura, Y. Suzuki, and T. Ueda: $J$. Radiat. Res., 18, 322-330 (1977).

10) T. Ueda, R. Nakamura, and Y. Suzuki: Bull. Japan. Soc. Sci. Fish., 42, 299-306 (1976).

11) T. Ueda, R. Nakamura, and Y. Suzuki: $J$. Radiat. Res., 18, 84-92 (1977).

12) T. Ueda, R. Nakamura, and Y. Suzuki: $J$. Radiat. Res., 19, 93-99 (1978).

13) Y. Suzuki, R. Nakamura, and T. Ueda: $J$. Radiat. Res., 17, 115-126 (1976).

14) A. H. Seymour and V. A. Nelson: in "Radioactive Contamination of the Marine Environment"' IAEA, Vienna, 1973, pp. 277-286. 